\title{
Addictive agents and intracranial stimulation (ICS): Naloxone blocks morphine's acceleration of pressing for ICS
}

\author{
MICHAEL A. BOZARTH and LARRY D. REID \\ Rensselaer Polytechnic Institute, Troy, New York 12181
}

\begin{abstract}
Ten rats were fixed with chronically indwelling electrodes for intracranial stimulation (ICS) of the lateral hypothalamus. The rats were then trained to press a lever for the selfadministration of ICS at two current intensities; one intensity produced a low rate of pressing and the other a high rate of pressing for ICS. Subsequent to obtaining stable press rates for each intensity of ICS, five rats received daily injections of morphine $(10 \mathrm{mg} / \mathrm{kg}) 4 \mathrm{~h}$ prior to testing and five rats were injected with saline. After a significant acceleration of pressing for ICS was demonstrated by the morphine group, both groups were injected with naloxone $(1 \mathrm{mg} / \mathrm{kg}) 15 \mathrm{~min}$ prior to testing. No effect was shown for the placebo group, while naloxone blocked morphine's potentiation of pressing for ICS. The blocking effect persisted for 3 days after the single dose of naloxone despite the continued administration of morphine $(10 \mathrm{mg} / \mathrm{kg} /$ day), which had previously accelerated pressing for ICS.
\end{abstract}

In rats fixed with chronically indwelling hypothalamic electrodes, injections of morphine reliably facilitate pressing for hypothalamic intracranial stimulation (ICS) (Adams, Lorens, \& Mitchell, 1972; Bush, Bush, Miller, \& Reid, 1976; Lorens \& Mitchell, 1973). The increase in pressing, induced by moderate doses of morphine, does not seem to be a consequence of morphine's analgesic capability (Farber \& Reid, 1976; Zipnick, Kelley, \& Reid, Note 1) nor related to a nonspecific, general excitatory effect (Koob, Spector, \& Meyerhoff, 1975; Lorens \& Mitchell, 1973). Furthermore, rats will move to places where they had previously experienced morphine's effects during the time when morphine produces the greatest acceleration in pressing. This last finding was interpreted as indicating that morphine elicits a positive affective state that corresponds to the time of morphine's acceleration of pressing for ICS (Rossi \& Reid, 1976). Also, the acceleration, once seen, does not appear to wane with assimilation of considerable morphine (Bush et al., 1976; Collaer, Magnuson, \& Reid, in press; Kelley \& Reid, 1977; Zipnick et al., Note 1). Since the effect does not seem to disappear with repeated dosing of morphine and since the effect is related to basic reinforcement processes, the processes reflected by morphine's acceleration of pressing for ICS could be an important factor in the maintenance of behavior of morphine assimilation.

Attempts (Koob et al., 1975; Pert, 1975; Overmeir \& Reid, Note 2) to see if the acceleration effect of

This research was supported by Grant DA 01049 from the National Institute of Drug Abuse, DHEW. Portions of this project were done at Bradley University, Peoria, Illinois. Endo Laboratories, Garden City, New Jersey, kindly provided the naloxone. morphine on pressing for ICS is blocked by naloxone have not yielded unequivocal results. Our first attempt (Overmeir \& Reid, Note 2) used rats injected with $10 \mathrm{mg} / \mathrm{kg}$ of morphine sulfate, with ICS testing $4 \mathrm{~h}$ after administration. Naloxone injections of $3 \mathrm{mg} / \mathrm{kg}$ reduced the acceleration in rats receiving morphine but also reduced pressing of rats getting a placebo injection. Therefore, it was impossible to discern whether the reduction in pressing was specific to the acceleration effect. Given the possibility that naloxone itself might reduce pressing for ICS, the results of Koob et al. (1975) showing that naloxone $(5 \mathrm{mg} / \mathrm{kg})$ blocked heroininduced acceleration of pressing for ICS were not convincing, since the reduction was not compared to extent of possible reduction without heroin injections. Pert (1975) found that naloxone $(2 \mathrm{mg} / \mathrm{kg})$ itself did not reduce pressing but that naloxone injection plus morphine produced a $60 \%$ decrease in pressing compared to baseline. Since our original dose of $3 \mathrm{mg} / \mathrm{kg}$ of naloxone by itself reduced pressing for ICS, we decided to test a smaller dose of naloxone on morphine-induced acceleration of pressing for ICS.

\section{METHOD}

\section{Subjects}

Ten experimentally naive male Holtzman rats weighing 260 to $370 \mathrm{~g}$ at the time of surgery were fixed with a chronically indwelling bipolar electrode. The stainless steel electrodes (Plastic Products 303) were insulated except at the cross sections of the tips. Electrode tips were aimed for the lateral hypothalamic area, a region in which ICS is positively reinforcing. The standard surgical procedures involved interperitoneal injections of sodium pentobarbital $(45 \mathrm{mg} / \mathrm{kg})$ and atropine sulfate $(.04 \mathrm{mg} / \mathrm{kg})$. Following surgery, and for the remainder of the behavioral testing, the subjects were individually housed and given free access to food and water. 


\section{Apparatus}

ICS was achieved by delivering a .25 -sec train of $60-\mathrm{Hz}$ sine waves at various intensities, but always less than 50 microA rms. The subjects were tested in an illuminated soundattenuating chamber $(24 \times 30 \times 35 \mathrm{~cm})$ fitted with a lever for the self-administration of ICS. Each leverpress yielded a single train of ICS. The electrode leads for delivering ICS were attached to a commutator mounted in the ceiling of the chamber, an arrangement that allowed the rats unhampered movement. Press rates were recorded automatically during 2-min trials.

\section{Procedure}

After a minimum of 5 days for recovery from surgery, each rat was trained to press for ICS at intensities from 20 to 40 microA. Subsequent to initial training, ICS intensities were varied and two intensities were selected for each subject. One intensity (ranging from 5 to 16 microA) sustained low rates of pressing (Lo ICS) and the other (ranging from 8 to 26 microA) sustained a high rate of pressing (Hi ICS).

After selection of intensities of ICS, rats were tested a minimum of 39 consecutive days with each intensity to insure consistent pressing rates at the prescribed intensities. A daily session was a 2 -min period with low-intensity ICS followed by a 2-min period with high intensity. A 1-min warmup period preceded each 2-min measurement. Rats were "primed" (i.e., given ICS by the experimenter while shaping to press), if necessary, during the warmup period.

After the days of stabilization, daily testing continued for 3 days, the resultant measurements being the first baseline. On the basis of their baselines, rats were matched and one of each pair was randomly assigned to receive morphine injections. After baseline, daily testing continued as before except that groups received daily injections.

One group of rats received 22 consecutive daily injections of $10 \mathrm{mg} / \mathrm{kg}$ morphine sulfate subcutaneously $4 \mathrm{~h}$ before the tests with ICS. The other group received physiological saline, the carrier of morphine, in doses of equal volume $(1 \mathrm{ml} / \mathrm{kg})$. On Day 19 of injections, both groups were also injected interperitoneally with $1 \mathrm{mg} / \mathrm{kg}$ naloxone hydrochloride $15 \mathrm{~min}$ before tests with ICS. All injections were terminated with Day 23 of testing but testing continued for 3 days, yielding measurements of the last baseline.

In summary, one group was tested for pressing for ICS under the influence of morphine, while the other was tested under a placebo. After morphine had clearly led to accelerated pressing, a single naloxone injection was given $15 \mathrm{~min}$ before testing in rats previously given morphine or placebo. Morphine and placebo injections were continued for 3 days after the naloxone injection. Both before and after these tests, there were tests without injections that constituted baselines of pressing.

\section{RESULTS}

A 2 by 2 by 6 analysis of variance (ANOVA) on repeated measures was done on the number of presses of the 3 days of baseline prior to injections and the 3 days of baseline following all injections. The ANOVA had the factors of the two groups (one of morphine injections and one of saline), the two ICS intensities, and the 6 days of testing. The results suggest no reliable differences between groups: mean pressing of rats of morphine, 120.7; mean pressing of rats of saline, 95.5 $[F(1,8)=.9, p>.3]$. Also, there was no reliable effect across days $[F(5,40)=1.2, p>.3]$. There was, of course, a reliable intensity effect: Mean pressing for lowintensity ICS was 31.8 presses $/ 2 \mathrm{~min}$, while mean pressing for high ICS was 184.3 presses $/ 2 \min [F(1,8)=$ $65.5, \mathrm{p}<.001]$. None of the interactions was a reliable source of variance. This analysis leads to the conclusion that pressing of the two groups did not differ before or after treatments and that any difference seen during treatments is an effect of treatments.

A summary of the effects of injections is presented in Figure 1. The values of Figure 1 are mean difference scores of each group across 3-day blocks of testing. A difference score was derived by taking a score after injections began and subtracting the comparable mean baseline score of the preinjection period. A negative score, therefore, indicates a decrease in pressing compared to initial baseline and a positive score indicates an increase in pressing. With difference scores, the potential variance attributable to intensities can be reduced considerably, since pressing at each intensity is assessed in terms of its own baseline.

A 2 by 2 by 6 ANOVA on repeated measures was done on the scores used to derive the scores of the first six blocks of testing in Figure 1. The ANOVA had factors of type of injections (morphine or saline), intensities, and the six blocks of tests. The results of the ANOVA confirmed that morphine reliably increased pressing compared to pressing under saline $[F(1,8)=$ $9.5, \mathrm{p}<.02]$ and that pressing increased reliably across

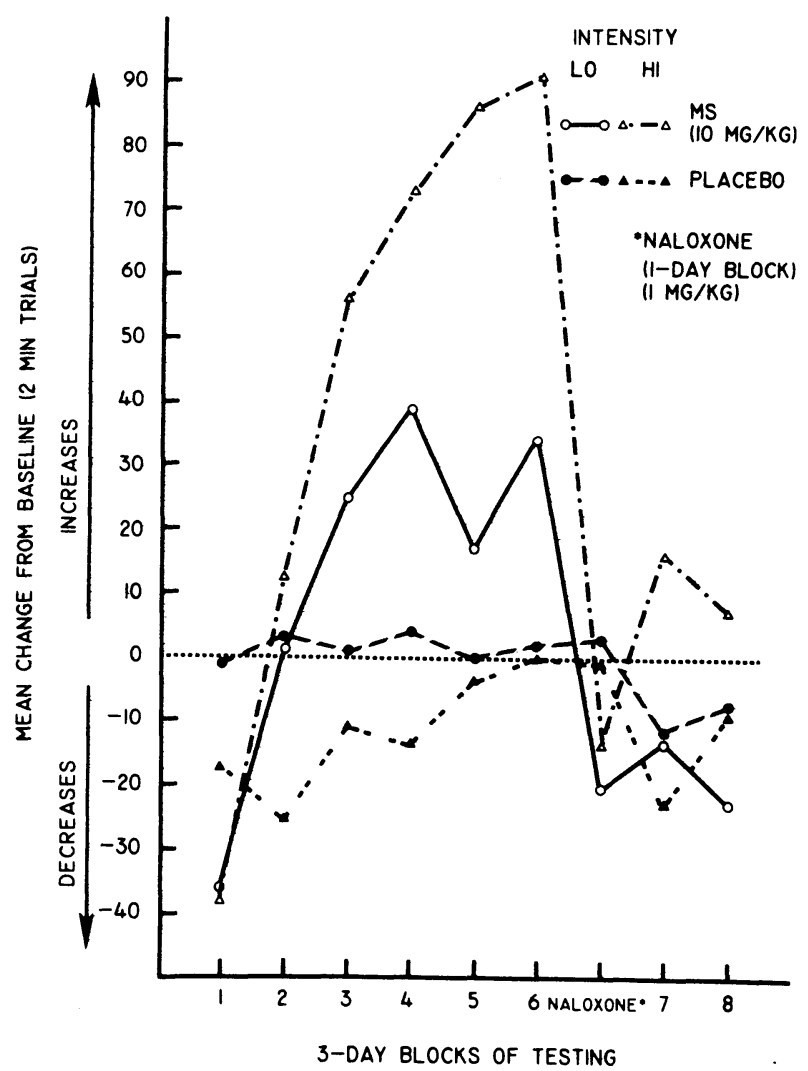

Figure 1. Mean difference scores (score minus mean of first baseline) for each group at each intensity. Each data point is the mean of 3 days of testing except that labeled "naloxone." 
blocks of testing $[F(5,40)=6.6, p<.001]$. There was also a reliable Groups by Days interaction $[F(5,40)=$ $4.4, p<.003]$. From Figure 1 and the analyses, it is clear that the rats performed as would be expected from the previous reports of the effects of morphine on pressing for ICS. The question, of course, was whether the acceleration in pressing would be eliminated by naloxone.

As depicted in Figure 1, the pressing of the rats under morphine plus naloxone or saline plus naloxione was about the same as initial baseline pressing for each intensity. Student's $t$ tests for correlated measures comparing mean baseline scores to scores under naloxone yielded ts (4) from 0 to .7 (ps $>.30)$. There were no reliable differences between scores of the two groups on the day of naloxone injections with low-intensity ICS $[\mathrm{t}(8)=1.2, \mathrm{p}>.20]$ nor with high-intensity ICS $[\mathrm{t}(8)=.5, \mathrm{p}>.20]$. A t test for correlated measures, on scores of rats of morphine, indicated a reliable reduction in pressing from Block 6 (morphine only) to Day 19 (morphine plus naloxone)[for low-intensity responding, $\mathrm{t}(4)=3.8, \mathrm{p}<.03$; for high-intensity responding, $\mathrm{t}(4)=2.6, \mathrm{p}<.05]$.

Subsequent to the day of administration of naloxone, the two groups continued to get their respective injections for 3 days (Block 7, Figure 1). Pressing under the morphine did not return to the levels of pressing in Block 6. The results of an ANOVA on the scores of Block 7 (Figure 1) gave no indication that the groups differed reliably during this period of testing $[F(1,8)=$ $1.3, \mathrm{p}>.25$ ] . As mentioned, Block 8 scores (last baseline) were similar to initial baseline scores and the scores of the two groups from Block 8 were not reliably different from one another.

Electrode placements were determined by photographic enlargements of frozen sections of the rats' brains. All electrode tips were in the dorsal perimeter of the lateral hypothalamus or subthalamus, including the specific structures of the medial forebrain bundle, zona incerta, and Forel's Fields.

\section{DISCUSSION}

Pressing for lateral hypothalamic ICS was increased with injections of morphine. The pressing was reduced to near baseline levels with an injection of naloxone. Naloxone, in amounts given, did not reliably modify pressing in rats preloaded only with saline. These results support the conclusion that morphine's acceleration of pressing is the result of a rather specific pharmacological process and not due to a rebound from a depression in activity, which would only be enhanced by naloxone, or due to general, nonspecific effects of behavior. The enhanced pressing for certain ICS following morphine or heroin injections is a rather specific effect, specific to positive ICS and specific to the action of the drugs on the tissue of positive ICS (Broekkamp, Van Den Bogaard, Heijnen, Rops, Cools, \& Van Rossum, 1976; Farber \& Reid, 1976; Koob et al., 1975; Lorens \& Mitchell, 1973; Pert, 1975).

Unexpectedly, pressing rates for ICS of the morphine group did not differ reliably from pressing rates of the control group (nor from baseline pressing) on days following naloxone administration even though the morphine injections continued for 3 days after the single day of naloxone administration. It is generally accepted that naloxone's antagonism of morphine's effects lasts only 1 to $4 \mathrm{~h}$ after a naloxone injection (Jaffe \& Martin, 1975). The data of this experiment, however, indicate that the effect of a single small dose of naloxone may reduce morphine-induced acceleration of pressing for ICS several days after the injection.

A flaw of our procedures is that we did not continue to test under morphine to see how long naloxone exerted its apparent effect. If the accelerated pressing for ICS induced by morphine reflects the positively reinforcing properties of morphine, then the possible prolonged antagonism of this effect is of considerable interest.

\section{REFERENCE NOTES}

1. Zipnick, J., Kelley, K., \& Reid, L. Addictive agents and intracranial stimulation (ICS): Daily morphine and pressing for combination of positive and aversive ICS. Under editorial review.

2. Overmeir, M., \& Reid, L. Addictive agents and intracranial stimulation (ICS): Effects of naloxone on morphine's acceleration of pressing for ICS. Unpublished manuscript.

\section{REFERENCES}

Adams. W. J., Lorens, S. A., \& Mitchell, C. L. Morphine enhances lateral hypothalamic self-stimulation in the rat. Proceedings of the Society of Experimental Biology and Medicine, 1972, 140, 770-771.

Broekkamp, C. L.. Van Den Bogatrd, J. H., Heijnen, H. J., Rops, R. H.. Cools, A. R., \& VAN Rossum, J. M. Separation of inhibiting and stimulating effects of morphine on selfstimulation behaviour by intracerebral microinjections. European'Jourmal of Pharmacology, 1976. 36. 443-446.

Bush, H. D.. Bush. M. F.. Miller, M. A.. \& Reid, L. D. Addictive agents and intracranial stimulation: Daily morphine and lateral hypothalamic self-stimulation. Physiological Psychology, 1976, 4. 79-85.

Collaer. M. L.. Magnuson. D. J., \& Reid, L. D. Addictive agents and intracranial stimulation (ICS): Pressing for ICS before and after self-administration of sweetened morphine solutions. Physiological Psychology, in press.

FARBER, P. D.. \& REID. L. D. Addictive agents and intracranial stimulation (ICS): Daily morphine and pressing for combinations of positive and negative ICS. Physiological Psychology, 1976, 4. 262-268.

JAFFE, J. H., \& MARTIN, W. R. Narcotic analgesics and antagonists. In L. S. Goodman \& A. Gilman (Eds.), The pharmacological basis of therapeutics (5th ed.). New York: MacMillan, 1975.

Kelley, K. L.. \& ReID, L. D. Addictive agents and intracranial stimulation: Morphine and thresholds for positive intracranial reinforcement. Bulletin of the Psychonomic Society, 1977, 10, 298-300.

Koob, G. F.. Spector, N. H., \& Meyerhoff, J. L. Effects of heroin on lever pressing for intracranial self-stimulation, food and water in the rat. Psychopharmacologia (Berlin), 1975, 42. 231-234.

Lorens, S. A., \& Mitchell, C. L. Influence of morphine on lateral hypothalamic self-stimulation in the rat. Psychopharmacologia (Berlin), 1973, 32, 271-277.

PERT, A. Effects of opiates on rewarding and aversive brain stimulation in the rat. Proceedings of the 37th annual scientific meeting committee on problems of drug dependence. Washington, D.C.. May 1975.

Rossi. N. A.. \& Reid, L. D. Affective states associated with morphine injections. Physiological Psychology, 1976, 4, 269-274.

(Received for publication August 15. 1977.) 